\title{
Life history of the false flower mantid (Harpagomantis tricolor Linnaeus, 1758) (Mantodea: Galinthiadidae) and its distribution in southern Africa
}

\author{
Bianca GreYvenstein', Hannalene du Plessis', Johnnie Van den Berg'
}

1 Unit for Environmental Sciences and Management, North-West University, Potchefstroom, 2520, South Africa.

Corresponding author: Bianca Greyvenstein (biagrey90@gmail.com)

Academic editor: Matan Shelomi | Received 1 April 2020 | Accepted 7 July 2020 | Published 18 February 2021

http://zoobank.org/C30EF79A-5544-450B-B439-8A4BB9DD9E2C

Citation: Greyvenstein B, du Plessis H, Van den Berg J (2021) Life history of the false flower mantid (Harpagomantis tricolor Linnaeus, 1758) (Mantodea: Galinthiadidae) and its distribution in southern Africa. Journal of Orthoptera Research 30(1): 17-26. https://doi.org/10.3897/jor.30.52816

\begin{abstract}
The false flower mantid is the common name for the Mantodea species Harpagomantis tricolor (Linnaeus, 1758). This species uses camouflage as a defense mechanism. Limited information (Kaltenbach 1996, 1998) exists on its distribution in southern Africa or about its life history. This species, and Mantodea to an extent, are not usually included in biodiversity studies from this region. The aim of this study was to determine the distribution of this species in southern Africa based on museum collection records and to study the biology of Harpagomantis tricolor under captive breeding conditions. The distribution of Harpagomantis and its morphological variety, i.e., discolor, were determined utilising the historical insect collection records of seven national museums throughout South Africa. Field collected H. tricolor males and females were mated and reared under laboratory conditions to record their life history parameters of nymphal duration, oothecae structure, size and incubation duration, adult longevity, and sex ratio. The results of this study indicate that the mean duration of the lifecycle of $\mathrm{H}$. tricolor is $191.33 \pm 37.96$ days. All but three $H$. tricolor individuals had five nymphal instars, and the mean duration of the nymphal stage was 140.20 \pm 31.03 days. The mean duration of copulation was six hours, while the average incubation period of oothecae was $144.71 \pm 9.33$ days. These results indicate that oothecae of $H$. tricolor probably overwinter under field conditions and that males of this species have evolved various mechanisms to increase the likelihood of ensuring their own genetic offspring. This study bridges the gap in rudimental research in which Mantodea, in general, has been overlooked and establishes a basis on which ecological interactions, habitat preferences, and imminent threats to $H$. tricolor can be established.
\end{abstract}

\section{Keywords}

camouflage, copulation, longevity, praying mantis

\section{Introduction}

Harpagomantis Kirby is one of four genera in the newly rearranged family of Galinthiadidae (Roy and Stiewe 2014, Svenson et al. 2015, Schwarz and Roy 2019). Within the Harpagomantis genus, there were two known species: Harpagomantis tricolor (Linnaeus, 1758) and Harpagomantis discolor (Stål, 1877). However, H. discolor was found to be a morphological variety of $H$. tricolor, and thus the only species within this genus is H. tricolor. Harpagomantis,
Galinthias, Congoharpax, and Pseudoharpax were previously classified as Hymenopodidae. However, due to molecular evidence and the phylogenetic results reported by Svenson and Whiting (2009) and Svenson et al. (2015), these genera were found to be outside of Hymenopodidae and were moved to the new family Galinthiadidae (Roy and Stiewe 2014). Svenson et al. (2015) reported that the high level of homoplasy in the external morphology of these mantids contributed to the discrepancies in species identification based on molecular and morphological characteristics, as these did not align. Thus, these genera were originally classified within the Hymenopodidae family. However, morphological characteristics were also used to aid the rearrangement of these families in an article in which the Mantodea order and its families were revised and rearranged (Schwarz and Roy 2019).

Harpagomantis have been described as "false flower" mantids and are pink with green bands and sometimes yellow eyes (Fig. 1). Harpagomantis are reported to live on flowers where they camouflage and wait motionlessly for prey (O'Toole 2003). Camouflage in mantid species has been reported as the primary defense mechanism of these insects (Edmunds 1971), and H. tricolor is no exception. It has been recorded during biodiversity survey studies in South Africa, largely in the western Cape region (Grobbelaar et al. 1999, Brand and Samways 2009, Magoba and Samways 2010) and the Highveld grassland biome (Botha et al. 2018, Greyvenstein et al. 2020b). However, the distribution of this species is based solely on studies by Kaltenbach $(1996,1998)$. The latter study found this genus widespread in southern Africa and included eight of the nine South African provinces and records from Botswana, Lesotho, Namibia, Zambia, and Zimbabwe.

Cardoso et al. (2020) recently reported being concerned about the worldwide decline in insect populations and that only $20 \%$ of the total insect diversity has been named. Research is required to bridge this gap in knowledge and correct the bias in insect studies that have largely focused on specific taxa such as butterflies and pollinators (Cardoso et al. 2020). Samways et al. (2020) indicated that mapping the distribution of specific species could contribute to determining their range expansion, threat identification, and habitat favorability. This will aid in bridging the gap in knowledge regarding the distribution, biology, and ecology of the majority of 
insect species. Similarly, Svenson et al. (2015) reported that the ecology of most Mantodea species remains unknown. Although various studies have been done on Mantodea ecology, very few have been conducted in South Africa and with species of this region. The information available about species' ecology, observations, and biology in South Africa is based on either citizen science or very old publications that could be outdated.

The aim of this study was to determine the distribution of the genus Harpagomantis in southern Africa and to study the biology of $H$. tricolor under captive breeding conditions.

\section{Materials and methods}

Species distribution database.-Distribution records of Harpagomantis spp. were collected during visits to the following institutions that host curated insect collections in South Africa: Ditsong Museum of Natural History (Pretoria), Agricultural Research Council (Biosystematics Division, Pretoria), National Museum (Bloemfontein), Albany Museum (Grahamstown), Rhodes University (Grahamstown), Durban Natural Science Museum, Iziko South African Museum (Cape Town), and KwaZulu-Natal Museum (Pietermaritzburg). Most specimens in these collections were previously identified by foreign visiting taxonomists, and many were sent for identification to the Vienna Museum in Germany, the University of Drexel in Philadelphia, USA, the Muséum national $\mathrm{d}^{\prime}$ Histoire naturelle (MNHN) in Paris, France, and the research collection of Nicolas Moulin in Montérolier, France.

Harpagomantis specimens and distribution labels were photographed (Canon D1300) and digitized, after which this data was used to compile a distribution database of the species. The database contains the following information for each specimen record: genus and species name (to the available level of identification), collector's details and collection date where available, and the geo-referenced locality. Scientific literature (Ehrmann 2002, Svenson 2015, Schwarz and Roy 2019) was used to determine the current nomenclature within the genus. All locality data were georeferenced using the principles suggested by Wieczorek et al. (2004). Subsequently, all coordinates were converted from degrees, minutes, and seconds (DMS) to decimal degrees (DD) (gps-coordinates.net). Decimal degrees were used for developing distribution maps for $H$. tricolor, the $H$. discolor variety, and the specimens that have not been morphologically distinguished in southern Africa by means of GIS software (ArcMaps, Version 10.6.1). The collection dates recorded for each specimen were used to generate intervals of 11 years (i.e., 18561867 and 1868-1879) to compile a graph indicating the number of specimens collected over time and during certain intervals.

Rearing and biology.-Specimens were collected in the Grassland biome in the North West and Free State provinces of South Africa during the summer of 2016/2017. Adults of these field-collected individuals were mated, and nymphs that emerged from oothecae were used to rear a sufficient number of individuals to observe under captive breeding and rearing conditions. A sub-sample of the field-collected specimens was identified by Nicolas Moulin (honorary associate to MNHN) to confirm the species identification.

For breeding purposes, pairs of males and females were placed in glass containers. Glass containers $(40 \mathrm{~cm} \times 20 \mathrm{~cm} \times 20 \mathrm{~cm})$ were used to ensure that ample space was available for the male to avoid sexual cannibalism before, during, or after mating. To further limit the likelihood that females would cannibalize the males, ample food was provided before the male was introduced into the breeding container. The duration of copulation was recorded per breeding pair (Fig. 1c). After copulation concluded, the male was removed from the breeding container. The terrariums $(15 \mathrm{~cm}$ $\times 10 \mathrm{~cm} \times 20 \mathrm{~cm}$ ) in which females were kept after mating were checked daily for the presence of oothecae that were laid overnight. Oothecae were removed and put into small containers $(5 \mathrm{~cm}$ diameter and $5 \mathrm{~cm}$ high) inside a desiccator. A humidity level of $68 \pm$ $5 \%$ was maintained in the closed desiccator, following the method described by Solomon (1951). The desiccator was kept in an insect rearing room at a temperature of $27 \pm 1{ }^{\circ} \mathrm{C}$ with a $14 \mathrm{~L}$ : $10 \mathrm{D}$ photoperiod cycle until nymphs emerged from the oothecae.

Rearing of nymphs was done under controlled conditions (Fig. 1d). Each specimen was placed into a terrarium $(7 \mathrm{~cm} \mathrm{di-}$ ameter and $15 \mathrm{~cm}$ high) with three holes (each $2 \mathrm{~cm}$ in diameter) covered with gauze to allow air flow. Thin twigs $(5 \mathrm{~mm} \times 10 \mathrm{~cm})$ were placed inside each jar for climbing and hanging purposes, especially during moults. Food was provided every second day at the same time as fine water mist was sprayed into each container. Live aphids (Brevicoryne spp.) (Hemiptera: Aphididae) were provided as food for first- to third-instar nymphs, after which live crickets (Acheta sp., Orthoptera: Gryllidae) of different sizes (nymphal instars, i.e., pinheads) were provided. After moulting to the secondinstar, nymphs were removed from the communal terrariums and placed in separate terrariums to prevent cannibalism. Nymphs were reared until adulthood, after which males and females were identified. This was done by counting the number of abdominal segments and the appearance of the wings. Harpagomantis tricolor females have shorter wings (barely covering the abdomen) and six abdominal segments, while males have eight segments and wings that are longer than the abdomen (McMonigle 2013, Fatimah et al. 2016, Brannoch et al. 2017) (Fig. 1a, b).

The following life history parameters were recorded during this study: size of oothecae, number of egg chambers inside fertilized and unfertilized oothecae, copulation duration, number of days between moults, and survival rate (based on nymphs reaching the adult phase). The mean number of days between moults and days to adulthood were calculated separately for males and females. The data discussed in this paper were recorded for 45 individuals (14 males and 31 females) that completed their life cycles. The mean duration of male and female life cycles was calculated, and the hatch and survival rates were determined. A distinction was also made between different types of oothecae, i.e., fertilized and unhatched (produced by field-collected females of which the mating status was not known). The length, width, and height of each ootheca were recorded based on descriptions by Brannoch et al. (2017). The ootheca length was measured along the area of emergence, excluding the residual process (Brannoch et al. 2017, Greyvenstein et al. 2020a). To determine the number of eggs per ootheca, oothecae were dorsally dissected along the length and inspected under a microscope, as was done by Greyvenstein et al. (2020a). Measurements of ootheca parameters were done as indicated in Fig. 1e.

Data analysis. - The descriptive statistics (means and standard error) and the statistical analyses of the developmental parameters were done using Statistica Version 13.3 (TIBCO Software Inc., 2017). Shapiro-Wilk normality test was used to determine if the data were normally distributed, and data that were not normally distributed were log-transformed. T-tests were used to determine if differences existed between the length, width, height, and the number of eggs per ootheca between the two types of oothecae (i.e., fertilized and unfertilized). T-tests were also used to determine if differences existed between the mean numbers of days between moults, adult longevity, and mean number of days required by nymphs to reach adulthood. 

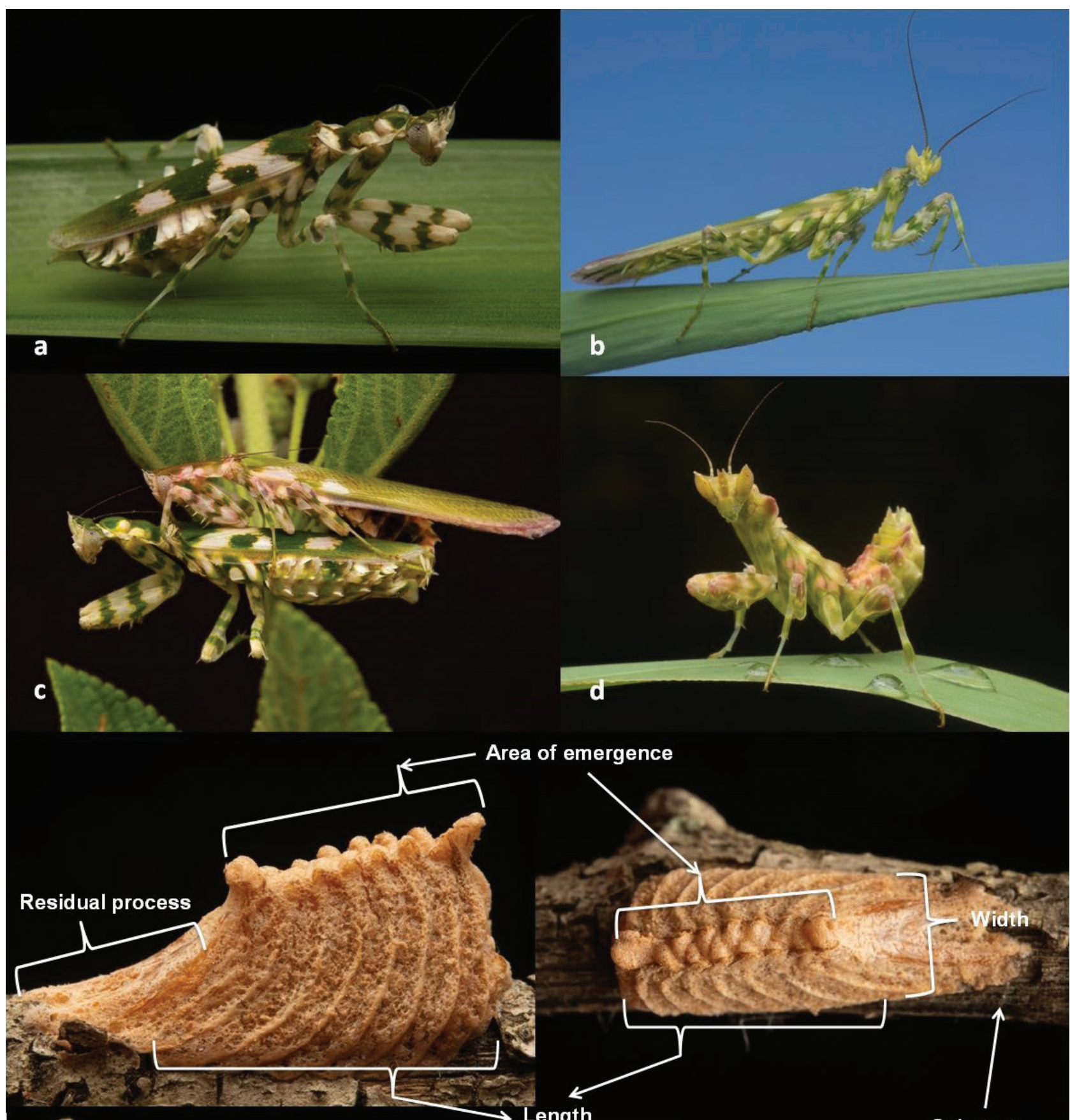

Area of emergence
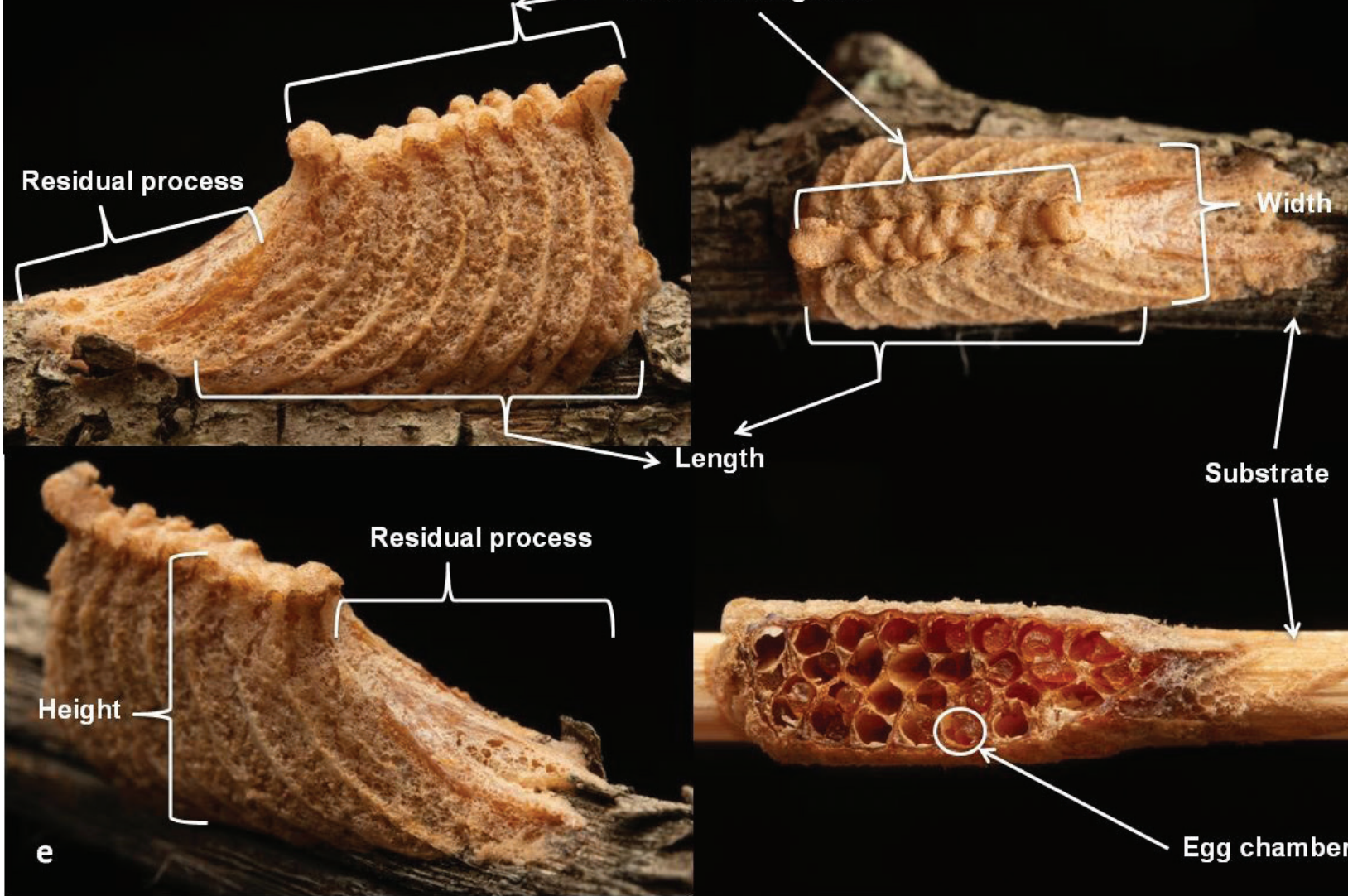

Length

Substrate

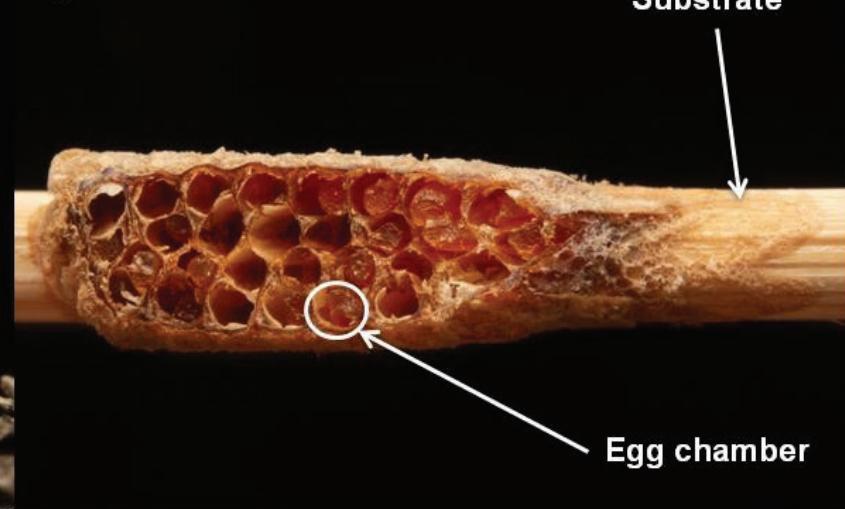

Fig. 1. Harpagomantis tricolor female. a. Male; b. Copulating adults; c. Fifth-instar nymph; d. General morphology of the oothecae; e. Indicating different parameters and areas of interest as suggested by Brannoch et al. (2017). Photographs by Paul Janse van Rensburg. 


\section{Results}

Distribution.-The distribution records reported in this paper were compiled from records available in the seven South African institutions that host curated arthropod collections. Results should be viewed in this context, since no museum records beyond those residing in South Africa were included. The results of this study and the following previously published studies (Kaltenbach 1996, 1998, Grobbelaar et al. 1999, Brand and Samways 2009, Magoba and Samways 2010, Botha et al. 2018, Greyvenstein et al. 2020b), to our knowledge, are the only studies to include distribution records of this species. The distribution records included records of Harpagomantis tricolor as well as the discolor morphological species variety from the following southern African counties: Botswana, Eswatini, Lesotho, Mozambique, Namibia, and Zimbabwe (Fig. 2).

A total of 290 specimen records were accounted for, of which 272 were collected within the borders of South Africa (this includes specimens collected in Lesotho and Eswatini). The remaining 18 records of $H$. tricolor were distributed as follows: two specimens collected in Botswana, six in Namibia, four in Mozambique, and six in Zimbabwe (Fig. 2). H. tricolor records were collected throughout South Africa and neighboring countries (Fig. 2). The distribution of H. tricolor in South Africa seems to be predominantly towards the eastern region of the country, with a few specimen records from the western region, specifically in the Western Cape Province (Fig. 2). The oldest H. tricolor specimen record was collected in 1876 in Cape Town. Only four specimens were collected between 1876 and 1887, while the largest number (37) were collected between 1912 and 1923 (Fig. 3). Between 1972 and 2019, the average number of specimens collected during the three 11 -year intervals was 31 (Fig. 3). Only 48 specimen records (18\%) were collected within protected areas of South Africa, while 224 records ( $82 \%)$ were collected outside these areas. These 48 specimens were collected in 11 different provincial nature reserves (19 records), four private nature reserves (14 records), two national parks ( 9 records), and one specimen was collected in each of a world heritage site, a protected forest area, and a local nature reserve (Fig. 4).

Biology.-The ootheca of $H$. tricolor is not covered in the usual foamy sheath that is characteristic of a variety of Mantodea, although exceptions do exist (McMonigle 2013). The oothecae are usually small, light brown in color, almost rectangular in shape, and slightly dorsally flattened (Fig. 1e). The residual process is not elongated or extended into any shape or point. In cases where the oothecae of $H$. tricolor were attached to the stem of a flowering plant in the field, they most likely resembled a thorn. Eggs were arranged in adjacent rows of between three and five eggs each (Fig. 1e). The residual process was also investigated but did not contain any egg chambers.

In this study, 19 oothecae were produced by field-collected females mated under captive breeding conditions. Seven of these did not hatch and 12 oothecae did hatch. In total, 63 nymphs emerged from the 12 fertile oothecae under captive breeding conditions. No significant differences were recorded between the length, width, height, or number of eggs of the fertilized or unhatched oothecae. Mean ootheca length was $8.5 \pm 4.11 \mathrm{~mm}$, containing $17.26 \mathrm{egg} \pm 6.66$ chambers per ootheca (Table 1 ). The mean width and height of an ootheca was $4.37 \pm 0.76 \mathrm{~mm}$ and $6.15 \pm 0.83 \mathrm{~mm}$, respectively (Table 1 ).

Developmental parameters.-Of the 63 neonate nymphs that hatched from the 12 different oothecae throughout this study, 45 completed their lifecycles (14 males and 31 females). The mean duration between mating and the production of an ootheca was

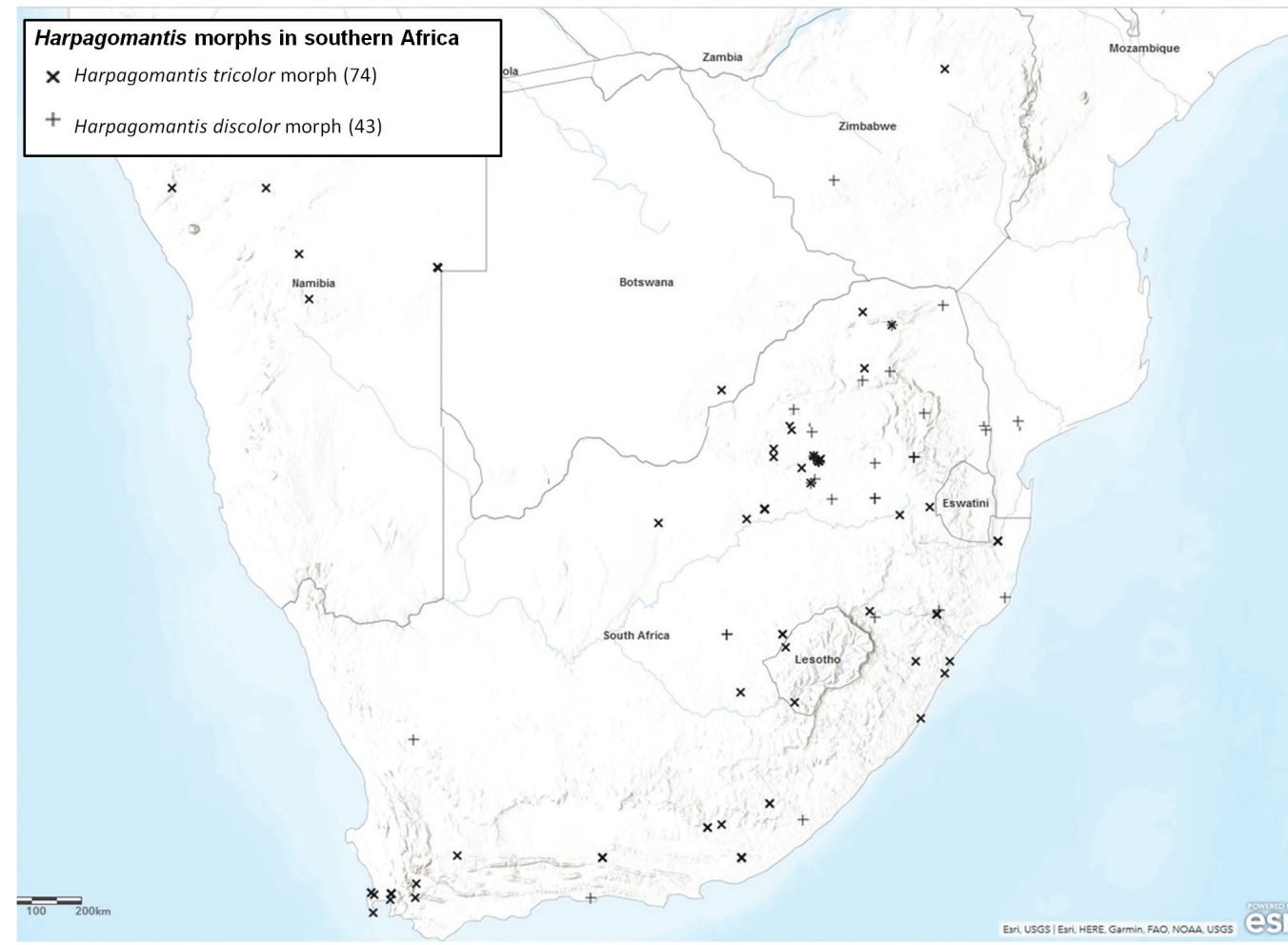

Fig. 2. Distribution records of Harpagomantis tricolor and its morph (discolor) that occur in southern Africa. Numbers in brackets indicate the number of individual records per variety. 
$11.82 \pm 9.51$ days, and the act of copulation itself continued for approximately six hours (Table 3 ). The incubation period of an ootheca was approximately 20 weeks (143 days). The mean hatch rate was $31 \%$, while the average survival rate was almost $68 \%$ (Table 2). The sex ratio differed between the various oothecae, but the mean sex ratio (M:F) was $1: 1.5$. Two of the oothecae produced only males, while another two produced only females (Table 2).
No significant differences were recorded between the average duration per instar of females and males. The nymphal period took approximately 20 weeks to complete (Table 3 ). However, females required a longer nymphal period (145.71 \pm 29.88 days $)$ than males $(128.00 \pm 31.09$ days $)$, even though this difference was not significant. The mean duration of the lifecycle of $H$. tricolor individuals in this study was six months (191.33 \pm 37.96 days).

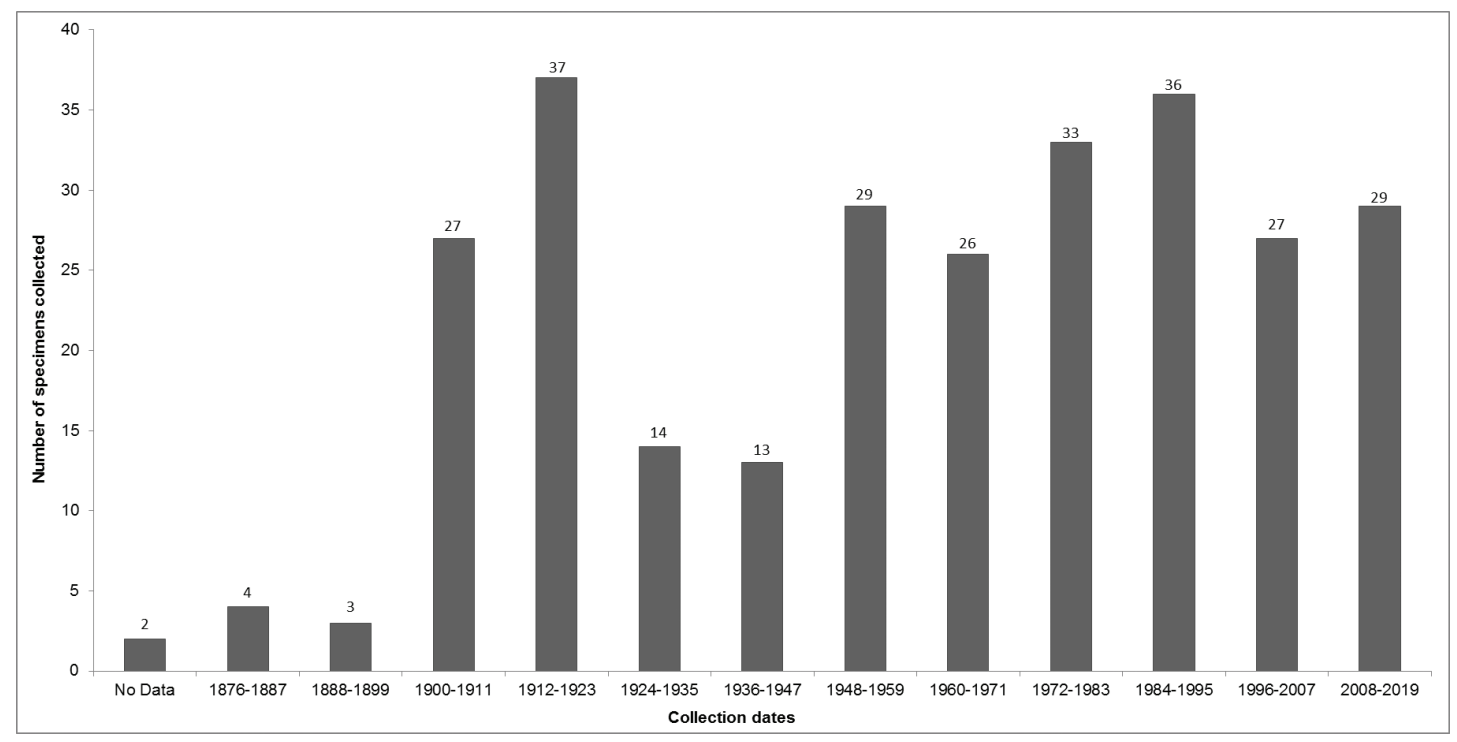

Fig. 3. Number of Harpagomantis species records collected in southern Africa during different time periods.

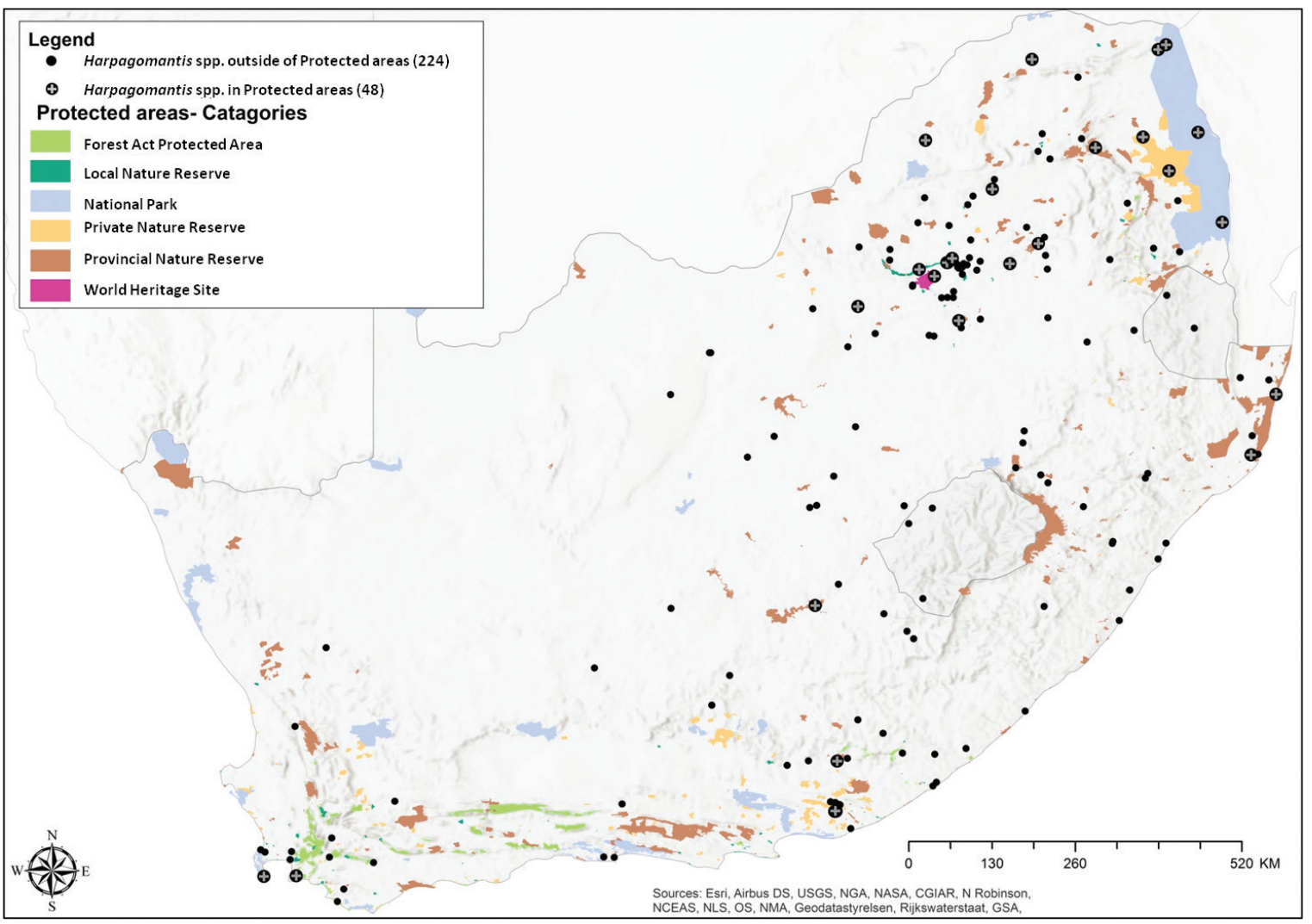

Fig. 4. Distribution records of Harpagomantis species collected in protected and non-protected areas of South Africa. 
Table 1. Mean size and number of egg chambers inside the various types of oothecae of Harpagomantis tricolor reared under captive breeding conditions. SD = standard deviation.

\begin{tabular}{|c|c|c|c|c|c|}
\hline \multicolumn{2}{|c|}{ Oothecae (19) } & Length $(\mathrm{mm}) \pm \mathrm{SD}$ & Width $(\mathrm{mm}) \pm$ SD & Height $(\mathrm{mm}) \pm \mathrm{SD}$ & Number of eggs/ootheca \pm SD \\
\hline \multirow[t]{2}{*}{ T-test } & t-value & 0.573 & 0.986 & 0.058 & 0.267 \\
\hline & p-value & 0.574 & 0.338 & 0.954 & 0.792 \\
\hline \multicolumn{2}{|c|}{ Overall (19) } & $8.58 \pm 4.11$ & $4.37 \pm 0.76$ & $6.15 \pm 0.83$ & $17.26 \pm 6.66$ \\
\hline \multicolumn{2}{|c|}{ Unhatched (7) } & $7.86 \pm 2.24$ & $4.14 \pm 0.69$ & $6.14 \pm 1.21$ & $16.71 \pm 7.20$ \\
\hline \multicolumn{2}{|c|}{ Fertilized (12) } & $9.00 \pm 4.63$ & $4.50 \pm 0.80$ & $6.17 \pm 0.58$ & $17.58 \pm 6.63$ \\
\hline
\end{tabular}

Table 2. Mean duration (in days) of each of the life stages of Harpagomantis tricolor and differences between male and female development under captive breeding and rearing conditions. Three of the females developed to the sixth-instar and were not included in the table below.

\begin{tabular}{|c|c|c|c|c|c|}
\hline \multirow[t]{2}{*}{ Life stage } & \multicolumn{3}{|c|}{ Mean duration (days \pm SD) } & \multirow[t]{2}{*}{ t-value } & \multirow[t]{2}{*}{ p-value } \\
\hline & Overall & Males & Females & & \\
\hline Ootheca (incubation period) & $144.71 \pm 9.33$ & $142.51 \pm 10.90$ & $145.68 \pm 8.55$ & 1.057 & 0.297 \\
\hline First instar & $26.62 \pm 11.07$ & $25.36 \pm 9.91$ & $27.1911 .67 \pm$ & 0.373 & 0.710 \\
\hline Second instar & $24.67 \pm 15.63$ & $28.57 \pm 17.51$ & $22.90 \pm 14.66$ & -1.110 & 0.273 \\
\hline Third instar & $27.67 \pm 13.06$ & $33.38 \pm 18.5$ & $25.42 \pm 9.37$ & -1.784 & 0.082 \\
\hline Fourth instar & $41.55 \pm 22.91$ & $49.00 \pm 29.63$ & $39.24 \pm 20.47$ & -0.838 & 0.407 \\
\hline Fifth instar & $51.50 \pm 13.28$ & $54.00 \pm 9.00$ & $51.06 \pm 14.06$ & -0.499 & 0.624 \\
\hline Copulation to oothecae (days)* & $11.82 \pm 9.51$ & $12.27 \pm 8.67$ & $11.63 \pm 9.99$ & -0.135 & 0.894 \\
\hline Copulation duration (hours) ${ }^{* *}$ & $06: 10 \pm 0.04$ & $06: 15 \pm 0.04$ & $06: 08 \pm 0.03 \pm$ & -0321 & 0.750 \\
\hline Total nymphal period (days) $* * *$ & $140.20 \pm 31.03$ & $128.00 \pm 31.09$ & $145.71 \pm 29.88$ & 1.776 & 0.082 \\
\hline Adult longevity (days) $* * * *$ & $51.11 \pm 39.76$ & $31.57 \pm 29.72$ & $59.93 \pm 40.97$ & -0.509 & 0.613 \\
\hline Period from hatch to death (days) & $191.33 \pm 37.96$ & $161.71 \pm 20.47$ & $204.71 \pm 36.58$ & -0.509 & 0.613 \\
\hline
\end{tabular}

* duration of period between male and female copulation and production of ootheca; ** duration of male and female copulation; *** from ootheca hatch to final moult (first-instar to fourth/fifth-instar); **** duration of adult phase.

Table 3. The mean hatch rate, survival rate, and gender dynamics that resulted from each of the field-collected $H$. tricolor females (12 individuals) that were kept in the laboratory and each of their associated fertile oothecae (12).

\begin{tabular}{|c|c|c|c|c|c|c|c|}
\hline Ootheca number & $\begin{array}{c}\text { Oothecae } \\
\text { incubation (days) }\end{array}$ & $\begin{array}{c}\text { No. of eggs per } \\
\text { ootheca }\end{array}$ & Hatch rate (\%) & Survival (\%) & Male (\%) & Female (\%) & Sex Ratio $(\delta:+)$ \\
\hline Ootheca 1 & 123 & 16 & 81.25 & 69.23 & 33.33 & 66.67 & $1: 2$ \\
\hline Ootheca 2 & 149 & 14 & 28.57 & 100 & 0.00 & 100.00 & $0: 4$ \\
\hline Ootheca 3 & 145 & 19 & 31.58 & 100 & 83.33 & 16.67 & $1: 0.2$ \\
\hline Ootheca 4 & 155 & 18 & 33.33 & 50 & 33.33 & 66.67 & $1: 2$ \\
\hline Ootheca 5 & 127 & 16 & 25.00 & 100 & 0.00 & 100.00 & $0: 4$ \\
\hline Ootheca 6 & 138 & 18 & 16.67 & 100 & 33.33 & 66.67 & $1: 2$ \\
\hline Ootheca 7 & 145 & 15 & 20 & 33.33 & 100.00 & 100.00 & $1: 1$ \\
\hline Ootheca 8 & 156 & 9 & 44.44 & 50 & 100.00 & 0.00 & $2: 0$ \\
\hline Ootheca 9 & 153 & 36 & 13.89 & 60 & 33.33 & 66.67 & $1: 2$ \\
\hline Ootheca 10 & 147 & 12 & 25.00 & 66.67 & 0.00 & 100.00 & $0: 2$ \\
\hline Ootheca 11 & 143 & 21 & 14.29 & 66.67 & 50.00 & 50.00 & $1: 1$ \\
\hline Ootheca 12 & 139 & 17 & 35.29 & 16.67 & 60.00 & 40.00 & $1: 0.67$ \\
\hline Mean $\pm(S D)$ & $143.33 \pm 10.31$ & $17.58 \pm 6.63$ & $30.78 \pm 18.35$ & $67.71 \pm 28.04$ & $43.89 \pm 36.15$ & $64.44 \pm 33.46$ & $1: 1.5$ \\
\hline
\end{tabular}

\section{Discussion}

Distribution patterns of Harpagomantis tricolor in southern Africa.-Although there have been some discrepancies in the past regarding the species within this genus, it is assumed that two morphological varieties exist: $H$. tricolor and $H$. discolor. Specimen records throughout the museum collections in South Africa exist for both morphological varieties (morphs). According to Stål (1877) and Giglio-Tos (1927), H. discolor males do not have a brown spot on the hindwings, and the species is generally larger than $H$. tricolor. Rehn (1927) reported that $H$. tricolor was a much smaller species with limited distribution (mostly in the Western Cape region of South Africa), while H. discolor occurs throughout South Africa but predominantly in the northern region. The latter species is also believed to be larger and have elongated processes on the eyes (non-visual elongations that do not contain ommatidia).

However, Karny (1908) indicated that $H$. discolor could be a variety of $H$. tricolor. This view was shared by Beier (1955), who stated that $H$. discolor was a "pigment-poor" variety of $H$. tricolor. A similar conclusion was drawn by Kaltenbach (1996), and this species was therefore considered an intra-species variety (in size and color) of $H$. tricolor and, according to Kaltenbach (1996), $H$. discolor is a synonym of $H$. tricolor. Ehrmann (2002) agreed with Beier $(1953,1955)$ and Kaltenbach (1996) and noted that H. discolor was a synonym for H. tricolor.

Rehn (1927) indicated the possibility of a clinal North-South differentiation between the two Harpagomantis morphs. Similarly, Kaltenbach (1994) noted a clinal variation of the subspecies of Bisanthe Stål, 1876, also in southern Africa. Kaltenbach (1994) de- 
scribed B. menyharthi menyharthi (Brancsik, 1895) to have a northern distribution (towards Zambia), while B. menyharthi raggei was recorded largely in the south towards Zimbabwe and Botswana (South of the Zambezi river). Although Kaltenbach (1994) indicated that temperature could have played a role in the clinal differentiation of the subspecies of Bisanthe in southern Africa, other factors could also be responsible for such observed differentiations. For example, Lombardo (1995) noted that the Great Rift Valley tectonic plate could be the dividing line between the clinal differentiations noted in the subspecies of Popa spurca Stål, 1856 (Popa spurca spurca Stål, 1856 and Popa spurca crassa Giglio-Tos, 1917 ) in Africa. The Great Rift Valley has been shown to be an important natural barrier for various invertebrate species, especially Busseola fusca (Fuller) (Lepidoptera: Noctuidae) and Sesamia cretica Lederer (Lepidoptera: Noctuidae), and is suspected to be the cause of their genetic differentiation into different clades towards the south, east, and west of the Rift Valley (Sezonlin et al. 2006, Assefa et al. 2015, Goftishu et al. 2016). This, as well as temperature (as indicated by Kaltenbach 1994), could be contributing factors to the differentiation reported in some African mantid species as well and should be further investigated. Despite this possible differentiation, the morphological variety, discolor, of $H$. tricolor remains a synonym, and thus only one species is known within the Harpagomantis genus.

The discolor variety of $H$. tricolor was last recorded in 1977 in Harkerville in the western Cape, while H. tricolor (except for the specimen collected during this study) was also collected in the western Cape during 2015 at Stellenbosch. It should further be noted that $176 \mathrm{H}$. tricolor specimens were recorded during this study; however, the morphological variety of these specimens could not be identified.

Literature on $H$. tricolor is somewhat scarce, but some studies have reported on the distribution of this genus. For example, in $1999, H$. tricolor was collected on an indigenous plant species, Delairea odorata (Asteraceae) (Cape Ivy), which occurs along the east coast of South Africa (Grobbelaar et al. 1999). This mantid species was also recorded in fynbos and native vegetation that were cleared of alien invasive trees (Magoba and Samways 2010) as well as in the De Hoop Nature Reserve, a World Heritage site in the western Cape (Brand and Samways 2009). Harpagomantis specimens were also recorded in the Highveld grassland biome of South Africa (Botha et al. 2018, Greyvenstein et al. 2020b). Beyond these studies, the distribution of this genus is recorded to be throughout South Africa, but predominantly in Western Cape, KwaZulu Natal, and Transvaal (Beier 1955). Patel et al. (2016) listed the distribution of this genus to include Botswana, Namibia, Mozambique, and Zimbabwe, which is similar to the distribution of the genus described by Kaltenbach (1996). As the results of this study indicate (Fig. 2), various regions in South Africa (i.e., the Northern Cape, Free State, and parts of the Eastern Cape) had very few to no distribution records. Thus, these regions should be the priority of future investigations to determine if the extent of the distribution of this mantid species as presented in this study is a true representation with regards to $H$. tricolor in South Africa. This will also shed some light on the fact that these areas might have been underrepresented or under-investigated in previous collection efforts and, thus, few museum specimens from within these regions exist.

Gillon and Roy (1968) reported that a similar species, Pseudoharpax virescences Serville, 1839 (Mantodea: Galinthiadidae), occurs from Senegal to Cameroon, while more recently Moulin et al. (2017) and Moulin (2018) reported Congoharpax aberrans La Greca, 1954, and various other Galinthiadidae species to be found in the western tropical African countries: the Congo Republic, DR Congo, Cameroon, Ghana, Ivory Coast, and Gabon. These regions should be investigated in the future, as they could be a possible habitat of $H$. tricolor beyond that recorded in this study. Similarly, museum specimen records in European countries should also be incorporated, and citizen science platforms, such as iNaturalist and iSpot, should be used to establish the distribution of this species.

Ecomorphs (morphologically similar characteristics that align with particular habitats, such as certain camouflage capabilities) of mantids such as Harpagomantis are suspected to have evolved several times in different geographic regions due to similar habitats and ecological pressures (Svenson and Whiting 2009, Wieland 2013, Svenson et al. 2015). The morphological foundation of Mantodea taxonomy has caused inconsistencies, since the biogeographical distribution of ecomorph species was not previously considered and because a range of species that are morphologically similar occur on other continents. For example, H. tricolor in South Africa and species of the genus Creobroter Audinet (Mantodea: Hymenopodidae) from India (More and Prashant 2018) are morphologically similar. Thus, future investigations could shed some light on the extent of differentiation between the North and South $H$. tricolor varieties.

Many specimens were collected in Gauteng province, which is the region in South Africa with the highest human population density. This high population density could explain the large numbers of specimens collected in this region (Greyvenstein et al. 2020a). However, as reported by Grytnes and Romdal (2008), this could also be due to ease of access to natural areas where specimens can be collected outside of protected areas. In this study, most specimens were collected in provincial nature reserves. Davis et al. (2005) indicated that the Department of Agriculture, Conservation, Environment and Land Affairs has focused on protecting as much local flora and fauna as possible in provincial and local nature reserves in highly populated areas throughout South Africa.

This study suggests that provincial nature reserves, more so than national parks, may create refuge areas for species in a mosaic of disturbed and highly populated areas. An example of a provincial and/or local area that can be regarded as a refuge for birds in highly developed areas was reported by Wang et al. (2013) in China, where the Hengshui Lake nature reserve, close to the city of Jizhou, was created as a safe place for migratory and endangered bird species. However, more research is needed to determine if protected areas serve as refuges for less mobile species such as mantids. Future investigations should, therefore, be conducted to determine if Harpagomantis species are still present within provincial nature reserves, as suggested by the historic specimen records.

Biology.-Since no previous information on the biology of $\mathrm{H}$. tricolor could be found, comparisons of its biology are made with species such as Ephestiasula pictipes Wood-Mason, 1879 (Mantodea; Hymenopodidae) (Vanitha et al. 2016), which is in the Hymenopodidae family, from where H. tricolor was moved based on molecular evidence (Svenson et al. 2015). Due to the lack of literature about the particular biological parameters measured in this study, the investigations reported by Vanitha et al. (2016) will be used for comparison purposes. The study by Gillon and Roy (1968) indicated various biological parameters of the related species Pseudoharpax virescences Serville, 1839 (Mantodea: Galinthiadidae) and will thus be also be used as a comparison to $H$. tricolor. The shapes of the oothecae of $H$. tricolor and $P$. virescences are similar, but $H$. tricolor oothecae are longer and wider than those of $P$. virescences. 
Larsen (2002) suggested that the structure and morphology of mantid oothecae provide them with the ability to survive harsh environmental conditions. The function of the shell shape of some mantid oothecae, for example that of Gongylus Thunberg, 1815 (Mantodea: Empusidae) and Empusa Illiger (Mantodea: Empusidae), is to divert heat (Larsen 2002). Another explanation for the unique shape and color of the oothecae of some species is that they aid in crypsis (Thomann 2002). The shape and color of H. tricolor oothecae resemble, to an extent, the tubercle or auxiliary buds of plants. This could be an adaptation of this mantid species to blend into its environment, which is suggested to be predominantly on flowering plants, thus allowing the oothecae to be more inconspicuous and limiting unwanted investigation from potential predators. The ootheca of $H$. tricolor is an example of the wide variety of structural diversity and cryptic adaptations that are found throughout the oothecae of Mantodea (Rivera and Svenson 2016). Their small size (length, width, and height) contributes to their inconspicuousness, especially on thorny vegetation. The frequency of $H$. tricolor oothecae attached to various plant species, as well as the placement of the oothecae on the plants themselves, should be investigated in the future to assess the possibility of oothecae structures as cryptic adaptations and their effectivity as such.

The number of eggs within the oothecae of $P$. virescences was reported to be between 12 and 13 hatchlings per oothecae (Gillon and Roy 1968). Unfortunately, no dissections were made by Gillon and Roy (1968); thus, the number of eggs was not reported. Suckling (1984) reported an average of 34 eggs per ootheca for Orthodera ministralis (Fabricius, 1775) (Mantodea: Mantidae), which is close to the maximum number of eggs recorded for $H$. tricolor in this study. No differences were observed between any of the size parameters of fertilized and unhatched oothecae in this study. This is in contrast to the significant differences in size of fertilized and unhatched oothecae of Galepsus lenticularis (Saussure, 1872) (Mantodea: Tarachodidae) (Greyvenstein et al. 2020a). Similarly, Greyvenstein et al. (2020a) reported differences with regards to the number of eggs inside fertilized and unhatched oothecae. This was not the case for $H$. tricolor, as no differences in this regard were recorded in this study. It was noted that no oothecae were laid by the captively reared adult females, which is also in contrast to results reported by Greyvenstein et al. (2020a) for G. lenticularis. The oothecae of G. lenticularis have been described as "primitive" and resembling that of the Blattodea (Ene 1964, Greyvenstein et al. 2020a), those of H. tricolor could suggest a more advanced species based on their evolutionary history. To this point, different behaviors and biological adaptations could also be a result of their different evolutionary histories. The difference in evolutionary traits/ages of the species, environmental stimuli, foodrelated resources, or survival strategies could have been the reason that the captively reared $H$. tricolor females did not oviposit unfertilized oothecae (oothecae produced without mating).

Developmental parameters.-The extended incubation period of $H$. tricolor oothecae (145 days) recorded in this study was much longer than that reported by Vanitha et al. (2016) for E. pictipes. It is possible that under natural environmental conditions, the oothecae of $H$. tricolor undergoes diapause during winter, but under captive rearing conditions at a constant temperature and humidity, this incubation period was shorter. Overwintering of oothecae has been reported for some Mantodea species, such as Brunneria borealis Scudder, 1896 (Mantodea: Coptopterygidae); Tenodera aridifolia sinensis Saussure, 1871 (Mantodea: Mantidae); and Mantis religiosa Linnaeus, 1758 (Mantodea: Mantidae) (Kaltenbach 1963, Berg et al. 2011, McMonigle 2013, Maxwell 2014, Svenson et al. 2015, Hurd et al. 2019).
A high hatch rate and low survival rate were reported by Vanitha et al. (2016) for E. pictipes, while the opposite was recorded for $H$. tricolor in this study. Hatch and survival rates can be influenced by frequency of feeding, food resources, genetics, and temperature, depending on the survival strategy of the species (Matthews and Matthews 1978, Hurd and Eisenberg 1984, Suckling 1984, Iwasaki 1996, Vanitha et al. 2016, Christensen and Brown 2018). The average duration of the period between mating and production of an ootheca in this study was 12 days, while E. pictipes only required a week to produce the first ootheca after females mated (Vanitha et al. 2016).

The average duration of copulation for $H$. tricolor was six hours. McMonigle (2013) reported that sperm transfer occurs within 30 minutes of the initial copulation action of mantids. The extended copulation period is suggested to be a form of safeguarding of the genetic prodigy of the male since this behavior results in decreased competition with other males (Prokop and Vaclav 2005). Beyond decreasing sperm competition, males in a better condition (fitness) were also reported to copulate longer with females (Prokop and Vaclav 2005, Holwell 2006). Strategic ejaculation and adjustment of developmental duration has also been reported in males of Pseudomantis albofimbriata (Stål, 1860) (Mantodea: Mantidae), when these males were reared in a male-dominated environment (Allen et al. 2011). The latter authors reported that male development was slower under conditions where many males were present, while the opposite was observed when many females were present. Allen et al. (2011) indicated that male mantids took longer to mature and suggested that this could indicate more investment in the development of testes. These males also copulated for a significantly longer time and transferred more sperm per copulation event (Allen et al. 2011). Multiple paternity has been documented for $T$. aridifolia by Watanabe et al. (2011) who suggested the existence of competition between males of the same mantis species for copulation or mating opportunities. It should be noted that the artificiality of the mating conditions within this study could have contributed to the mating behavior results; however, the possible stress induced by the artificiality was reduced as much as possible by, for example, ensuring the container in which mating occurred was ample, that individuals collected from the field were only bred with after two days to allow the insects to acclimate to the artificial conditions of the container, and that the container was not moved or disturbed when the breeding pair were introduced to the single container but only observed to record the data.

Sexual dimorphism in size where males are smaller than females has been observed in various mantid species (Wieland 2013). Some examples of mantid species with size sexual dimorphism are Creobroter sp. Stål, 1877 (Hymenopodidae), Polyspilota aeruginosa (Goeze, 1778) (Mantidae), Parasphendale sp. (Miomantidae), and Theopropus elegans (Westwood, 1832) (Mantidae) (McMonigle 2013). Differences in size and color between sexes were noted for $H$. tricolor in this study. However, the duration of the adult stages did not differ significantly between males and females of $H$. tricolor. Differences in antennal morphology were also noted between male and female $T$. aridifolia from the sixth instar onwards (Carle et al. 2014). Pseudomantis albofimbriata (Stål, 1860) and G. lenticularis exhibit sexual dimorphism, as the wings of males are fully developed while females are flightless (Holwell et al. 2006, Greyvenstein et al. 2020a). Sexual dimorphism between males and females in wings and size could be due to the males having to find potential reproductive partners. Males of a smaller size could be more cryptic and more difficult to observe by predators. The smaller size of males also has dispersal advantages, as it could increase their ease of flight. 


\section{Conclusions}

This study is the first attempt at mapping the distribution of Harpagomantis in South Africa and recording the biology of H. tricolor. The distribution of false flower mantids in South Africa seems to be predominantly towards the northeastern region, in the savanna and grassland biomes. Extended copulation duration of this species could be a by-product of males trying to decrease sperm competition, which could also have led to the short duration of the male nymphs compared to female nymphs of $H$. tricolor. It is suggested that this species goes into diapause in the ootheca phase.

\section{Acknowledgements}

We would like to thank the following people at each of these institutions for allowing us to access the collections: Audrey Ndaba at Ditsong Museum of Natural History (Pretoria), Vivienne Uys at the Agricultural Research Council (Biosystematics Division), Asley- Kirk Springs and Burgert Muller at the National Museum (Bloemfontein), Helen James and Musa Mlambo at the Albany Museum (Grahamstown), Martin Hill and Thabisa Mdlangu at Rhodes University (Grahamstown), Kirstin Williams at the Durban Natural Science Museum, Tricia Pillay at KwaZulu Natal Museum (Pietermaritzburg), and Aisha Mayekiso at Iziko Museum of South Africa (Cape Town). We also thank Simon van Noort at Iziko Museum of South Africa, Entomology Specify. The National Research Foundation of South Africa contributed funding to this project (grant number: 101176). Lastly, we thank Nicolas Moulin for his expertise in identifying the sub-sample of species used for the biological aspect of this study.

\section{References}

Allen LE, Barry KL, Holwell GI, Herberstein ME (2011) Perceived risk of sperm competition affects juvenile development and ejaculate expenditure in male praying mantids. Animal Behaviour 82: 1207-1206. https://doi.org/10.1016/j.anbehav.2011.09.009

Assefa Y, Conlong DE, van den Berg J, Martin LA (2015) Ecological genetics and host range expansion by Busseola fusca (Lepidoptera: Noctuidae). Environmental Entomology 44: 1265-1274. https://doi.org/10.1093/ ee/nvv079

Beier M (1953) Some new and interesting South African mantids from the Transvaal Museum. Annals of the Transvaal Museum 22: 255-262.

Beier M (1955) Chapter VIII: Mantidea. In: B Hanström, P Brinck, G Rudebeck (Eds) South African animal life. Results of the Lund University Expedition in 1950-1951 (Vol. 2). Almqvist \& Wiksell, Stockholm, 234-265.

Berg MK, Schwarz CJ, Mehl JE (2011) Die Gottesanbeterin, Mantis religiosa: Die Neue Brehm-Bücherei. Westarp Wissenschaften, Hohenwarsleben, 33 pp.

Botha M, Siebert SJ, van den Berg J, Ellis S, Greyvenstein BM (2018) Diversity patterns of selected predaceous arthropod groups in maize fields and margins in South African Highveld grassland. Agricultural and Forest Entomology 20: 461-475. https://doi.org/10.1111/afe.12277

Brand MR, Samways MJ (2009) Comparative impact of invasive alien trees and vineyards on arthropod diversity in the Cape Floristic Region, Western Cape. MSc dissertation. University of Stellenbosch, Stellenbosch, South Africa, 296 pp.

Brannoch SK, Wieland F, Rivera J, Klass K, Bethoux O, Svenson GJ (2017) Manual of praying mantis morphology, nomenclature and practices (Insect, Mantodea). ZooKeys 696: 1-100. https://doi.org/10.3897/ zookeys.696.12542

Cardoso P, Barton PS, Birkhofer K, Chichorro F, Deacon C, Fartmann T, Fukushima CS, Gaigher R, Habel JC, Hallmann CA, Hill MJ, Hochkirch A, Kwak ML, Mammola S, Noriega JA, Orfinger AB, Pe- draza F, Pryke JS, Roque FO, Settle J, Simaika JP, Stork NE, Suhling F, Vorster C, Samways MJ (2020) Scientists' warning to humanity on insect extinctions. Biological Conservation 242: 1-13. https://doi. org/10.1016/j.biocon.2020.108426

Carle T, Yamawaki Y, Watanabe H, Yokohari F (2014) Antennal development in the praying mantis (Tenodera aridifolia) highlights multitudinous processes in Hemimetabolous insect species. PLoS ONE 9: 1-14. https://doi.org/10.1371/journal.pone.0098324

Christensen T, Brown WD (2018) Population structure, movement patterns, and frequency of multiple matings in Tenodera sinensis (Mantodea: Mantidae). Environmental Entomology 47: 676-683. https://doi.org/10.1093/ee/nvy048

Davis ALV, Scholtz CH, Deschodt C (2005) A dung beetle survey of selected Gauteng nature reserves: implications for conservation of the provincial scarabaeine fauna. African Entomology 13: 1-16. https:// hdl.handle.net/10520/EJC32629

Edmunds M (1971) Defensive behaviour in Ghanaian praying mantids. Zoological Journal of the Linnean Society 51: 1-32. https://doi. org/10.1111/j.1096-3642.1972.tb00771.x

Ehrmann R (2002) Mantodea: Gottesanbeterinnen der Welt. Natur und Tier Verlag: Munster, 519 pp.

Ene JC (1964) The distribution and post-embryonic development of Tarachodes afzelii (Stål), (Mantodea: Eremiaphilidae). Annals and Magazine of Natural History 7: 493-511. https://doi. org/10.1080/00222936408651488

Fatimah S, Sultana R, Wagan MS (2016) Study on the gender identification of praying mantids (Dictyoptera: Mantodea). Journal of Entomology and Zoology Studies 4: 529-531.

Giglio-Tos E (1927) Mantidae. In: Das Tierreich: Eine Zusamenstellung und Kennzeichnung der rezenten Tierforrnen Lieferung (eds. FE Schulze \& W Kukenthal). Walter de Gruyter \& Co.: Berlin, 650-592.

Gillon Y, Roy R (1968) Les Mantes de Lamto et des savanes de Côte d'Ivoire. Bulletin de l'IFAN. Série A - Sciences Naturelles 30: 1038-1151.

Goftishu M, Assefa Y, Fininsa C, Niba A, Capdevielle-Dulac C, Le Ru BP (2016) Phylogeography of Sesamia cretica Lederer (Lepidoptera: Noctuidae). Phytoparasitica 44: 641-650. https://doi.org/10.1007/ s12600-016-0556-8

Greyvenstein B, Du Plessis H, Moulin N, van den Berg J (2020a) Distribution of Galepsus spp. in Southern Africa and life history of Galepsus lenticularis (Mantodea: Tarachodidae). Insects 11: 1-17. https://doi. org/10.3390/insects 11020119

Greyvenstein B, Siebert SJ, van den Berg J (2020b) Effect of time of day on efficacy of sweep net sampling of arthropod predators in maize agro-ecosystems in the North West Province, South Africa. African Entomology 28: 150-163. https://doi.org/10.4001/003.028.0150

Grobbelaar E, Neser S, Neser OC (1999) Biological control of Delairea odorata in California: a survey for its insect natural enemies in South Africa. A report to the Agricultural Research Service, United States Department of Agriculture. Agricultural Research Council: Pretoria, South Africa, 64 pp.

Grytnes J, Romdal TS (2008) Using museum collections to estimate diversity patterns along geographical gradients. Folia Geobotanica 43: 357-359. https://doi.org/10.1007/s12224-008-9017-6

Holwell GI, Barry KL, Herberstein ME (2006) Mate location, antennal morphology, and ecology in two praying mantids (Insecta: Mantodea). Biological Journal of the Linnean Society 91: 307-313. https:// doi.org/10.1111/j.1095-8312.2007.00788.x

Hurd LE, Eisenburg RM (1984) Experimental density manipulations of the predator Tenodera sinensis (Orthoptera: Mantidae) in an old-field community. I. Mortality, development and dispersal of juvenile mantids. Journal of Animal Ecology 53: 269-281. https://doi.org/10.2307/4356

Hurd LE, Cheng KX, Abcug J, Calhoun LV, Geno ME, Merhige RR, Rosenthal IH (2019) Climate change, succession, and reproductive success of a praying mantid. Annals of the Entomological Society of America saz070: 1-5. https://doi.org/10.1093/aesa/saz070

Iwasaki T (1996) Comparative studies on the life histories of two praying mantises, Tenodera aridifolia (Stoll) and Tenodera angustipennis Saussure (Mantodea: Mantidae) I. Temporal pattern of egg hatch and nym- 
phal development. Applied Entomology and Zoology 31: 345-356. https://doi.org/10.1303/aez.31.345

Kaltenbach AP (1963) Kritische Untersuchungen zur Systematik, Biologie und Verbreitung der europäischen Fangheuschrecken (Dictyoptera Mantidae). Zoologische Jahrbücher Abteilung Systematik 90: 521-598.

Kaltenbach AP (1994) Bisanthe menyharthi (Brancsik, 1895): Klinale Variation, Subspecies-Bildung und geographische Verbreitung (Insecta: Mantodea: Mantidae). Annalen des Naturhistorischen Museums in Wien - Serie B für Botanik und Zoologie 96: 59-67.

Kaltenbach AP (1996) Unterlagen für eine Monographie der Mantodea des südlichen Afrika: 1. Artenbestand, geographische Verbreitung und Ausbreitungsgrenzen (Insecta: Mantodea). Annalen des Naturhistorischen Museums in Wien 98: 193-346.

Kaltenbach AP (1998) Unterlagen für eine Monographie der Mantodea (Insecta) des südlichen Afrika: 2. Bestimmungstabellen für die höheren Taxa, Nachträge zum Artenbestand. Annalen des Naturhistorischen Museums in Wien 100: 19-59.

Karny H (1908) Orthoptera (I.) Blattaeformia Oothecaria. In: Schultze L (Ed.) Zoologische und anthropologische Ergebnisse einer Forschungsreise im westlichen und zentralen $S^{\prime}$ dafrika-Denkschriften der medizi-ch - naturwissenschaftlichen Gesellschaft zu. Jenaische Denkschriften, Berlin, 335-390.

Larsen T (2002) The wandering violin: spotlight on Gongylus gongyloides. Invertebrate 1: 4-9.

Lombardo F (1995) A review of the genus Popa Stål, 1856 (Insecta Mantodea). Tropical Zoology 8: 257-267. https://doi.org/10.1080/039469 75.1995 .10539285

Magoba RNN, Samways MJ (2010) Comparative impact of invasive alien trees and vineyards on arthropod diversity in the Cape Floristic Region, Western Cape. PhD thesis, University of Stellenbosch, Stellenbosch.

Matthews RW, Matthews JR (1978) Insect Behaviour. John Wiley \& Sons: New York, 507 pp.

Maxwell M (2014) Developmental patterns in Stagmomantis limbata (Mantodea: Mantidae): variation in instar number, growth, and body size. Journal of Orthoptera Research 23: 49-58. https://doi.org/10.1665/034.023.0104

McMonigle O (2013) Keeping the Praying Mantis. Coachwhip Publications, Greenville, $202 \mathrm{pp}$.

More SV, Prashant MS (2018) Diversity of praying mantids from Tilari forest, Chandgad, Kolhapur district of Maharashtra India. International Journal of Entomology Research 3: 57-64.

Moulin N, Decaëns T, Annoyer P (2017) Diversity of mantids (Dictyoptera: Mantodea) of Sangha-Mbaere Region, Central African Republic, with some ecological data and DNA barcoding. Journal of Orthoptera Research 26: 117-141. https://doi.org/10.3897/jor.26.19863

Moulin N (2018) Liste commentée et catalogue illustré des Mantodea du Gabon. Les cahiers de la fondation Biotope 24: 2-60.

O'Toole C (2003) Preying for dinner-time. Nature 422: 564-565. https:// doi.org/10.1038/422564b

Patel S, Singh G, Singh R (2016) Global distribution of Empusidae, Eremiaphilidae, Galinthiadidae and Iridopterygidae (Mantodea: Dictyoptera: Insecta): A Checklist. International Journal of Zoological Investigations 2: 219-236.

Prokop P, Vaclav R (2005) Males respond to the risk of sperm competition in the sexually cannibalistic praying mantis, Mantis religiosa. Ethology 111: 836-848. https://doi.org/10.1111/j.1439-0310.2005.01113.x

Rehn JAG (1927) Contributions to our knowledge of the Dermaptera and Orthoptera of the Transvaal and Natal - Part II: Mantidae. Annals of the Transvaal Museum 12: 1-54.

Rivera J, Svenson GJ (2016) The Neotropical 'polymorphic earless praying mantises' - Part I: molecular phylogeny and revised higher-level systematics (Insecta: Mantodea, Acanthopoidea). Systematic Entomology 41: 607-649. https://doi.org/10.1111/syen.12178
Roy R, Stiewe M (2014) Révision du genre Galinthias Stål, 1877 (Mantodea, Galinthiadidae). Bulletin de la Société Entomologique de France 119: 199-215.

Samways MJ, Barton PS, Birkhofer K, Chichorro F, Deacon C, Fartmann T, Fukushima CS, Gaigher R, Habel JC, Hallmann CA, Hill MJ, Hochkirch A, Kaila L, Kwak ML, Maes D, Mammola S, Noriega JA, Orfinger AB, Pedraza F, Pryke JS, Roque FO, Settele J, Simaika JP, Stork NE, Suhling F, Vorster C, Cardoso P (2020) Solutions for humanity on how to conserve insects. Biological Conservation 242: 1-15. https:// doi.org/10.1016/j.biocon.2020.108427

Schwarz CJ, Roy R (2019) The systematics of Mantodea revisited: an updated classification incorporating multiple data sources (Insecta: Dictyoptera). Annales Societe Entomologique de France 55: 101-196. https://doi.org/10.1080/00379271.2018.1556567

Sezonlin M, Dupas S, Le Rü B, Faure N, Le Gall P, Silvain J (2006) Phylogeographic pattern and regional evolutionary history of the maize stalk borer Busseola fusca (Fuller) (Lepidoptera: Noctuidae) in sub-Saharan Africa. Annales de la Société entomologique de France 42: 339-351. https://doi.org/10.1080/00379271.2006.10697466

Solomon ME (1951) Control of humidity with potassium hydroxide, sulphuric acid or other solutions. Bulletin of Entomological Research 42: 543-554. https://doi.org/10.1017/S0007485300028947

Stål C (1877) Systema Mantodeorum. Essai d'une systématisation nouvelle des Mantodées. Bihang till Kongliga Svenska Vetenskaps Akademiens Handlingar 4: 1-91.

Suckling DM (1984) Laboratory studies on the praying mantis Orthodera ministralis (Mantodea: Mantidae). New Zealand Entomologist 8: $96-$ 101. https://doi.org/10.1080/00779962.1984.9722478

Svenson GJ, Whiting MF (2009) Reconstructing the origins of praying mantises (Dictyoptera, Mantodea): the roles of Gondwanan vicariance and morphological convergence. Cladistics 25: 468-514. https:// doi.org/10.1111/j.1096-0031.2009.00263.x

Svenson GJ, Hardy NB, Wightman HMC, Wieland F (2015) Of flowers and twigs: phylogenetic revision of the plant-mimicking praying mantises (Mantodea: Empusidae and Hymenopodidae) with a new suprageneric classification. Systematic Entomology 40: 789-834. https://doi. org/10.1111/syen.12134

Thomann CH (2002) Central-southeastern U.S. mantid Stagmomantis carolina (Johansson 1763). Invertebrate 4: 1-3.

TIBCO Software Inc (2017) Statistica (data analysis software system), version 13.3. http://statistica.io

Vanitha K, Bhat PS, Raviprasad TN, Srikumar KK (2016) Biology and behaviour of Ephestiasula pictipes (Wood-Mason) (Hymenopodidae: Mantodea) under captive breeding. International Journal of Pest Management 62: 308-318. https://doi.org/10.1080/09670874.2016. 1195026

Wang PEY, Xiaomei Deng X, Marcucci DJ, Le Y (2013) Sustainable Development Planning of Protected Areas near Cities: Case Study in China. Journal of Urban Planning and Development 139: 133-143. https:// doi.org/10.1061/(ASCE)UP.1943-5444.0000133

Watanabe E, Adachi-Hagimori T, Miura K, Maxwell MR, Ando Y, Takematsu Y (2011) Multiple paternity within field-collected egg cases of the praying mantid Tenodera aridifolia. Annals of the Entomological Society of America 104: 348-352. https://doi.org/10.1603/ AN10035

Wieczorek J, Guo Q, Hijmans RJ (2004) The point-radius method for georeferencing locality descriptions and calculating associated uncertainty. International Journal of Geographical Information Science 18: 745-767. https://doi.org/10.1080/13658810412331280211

Wieland F (2013) The phylogenetic system of Mantodea (Insecta: Dictyoptera). Species, Phylogeny and Evolution 3: 3-222. https://doi. org/10.17875/gup2013-711 